Academic Platform Journal of Engineering and Science

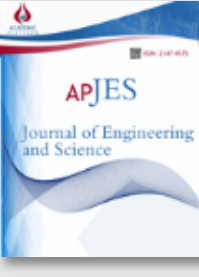

\title{
Bira Endüstrisi Atıksularının Elektrokoagülasyon ile Arıtımı ve Hibrit Elektrot Bağlantısının Etkisi
}

\author{
${ }^{1}$ Murat Eyvaz \\ ${ }^{1}$ Gebze Teknik Üniversitesi, Çevre Mühendisliği Bölümü, 41400, Gebze-Kocaeli, Türkiye, \\ meyvaz@gtu.edu.tr iD
}

Araștırma Makalesi

Geliş Tarihi: 05.08.2019

Kabul Tarihi: 02.12.2019

$\ddot{\mathbf{O} z}$

$\mathrm{Bu}$ çalışmada bir bira fabrikasına ait atıksuyun arıtımında anot ve katotu farklı metallerden oluşturulmuş elektrokoagülasyon (EC) yöntemi kullanılarak prosesin arıtma performansı ve işletme maliyeti analiz edilmiştir. Kesikli işletilen bir EC tankı içerisine demir $(\mathrm{Fe})$ ve alüminyum $(\mathrm{Al})$ elektrotlar sekiz farklı anot-katot-anot-katot (A-C-A-C) kombinasyonunda (Al-Al-Al$\mathrm{Al}$, Fe-Fe-Fe-Fe, Al-Fe-Fe-Fe, Al-Fe-Fe-Al, Al-Fe-Al-Fe, Fe-Al-Al-Al, Fe-Al-Al-Fe, Fe-Al-Fe-Al) dizilerek, prosesin atıksudan KOİ ve bulanıklık giderme verimleri ile işletme maliyetleri üzerine $\mathrm{pH}$, akım yoğunluğu ve elektroliz süresinin etkileri incelenmiştir. Çalışma sonunda optimum olarak bulunan EC şartlarında (pH 7, akım yoğunluğu: $60 \mathrm{~A} / \mathrm{m}^{2}$ ve elektroliz süresi: 30 dak.) KOİ ve bulanıklık giderme verimleri demir elektrotlar (Fe-Fe-Fe-Fe) kullanıldığında sırasıyla \%80 ve \%92 olurken, demiralüminyum hibrit bağlantılı (Fe-Al-Fe-Al) EC reaktöründe ise \%91 ve \%97 olarak gerçekleşmiştir. Bir metreküp bira endüstrisi atıksuyunun seçilen optimum şartlar altında EC ile arıtımının işletme maliyeti 35 TL olarak bulunurken, bir kg KOİ gideriminin maliyeti ise $\sim 12 \mathrm{TL}$ olarak hesaplanmıştır. Çıkış suyu karakteristikleri dikkate alındığında, gelecekteki çalışmalarda hibrit elektrot bağlantılı EC sisteminin benzer nitelikteki endüstriyel atıksular için bir ön arıtma yöntemi olarak kullanılabileceği ve yüksek KOİ konsantrasyonlarını bertaraf edebilecek bir anaerobik proses ile desteklenebileceği veya bir oksidasyon prosesini takiben, çıkış suyunu iyileştirme amacıyla son arıtma olarak değerlendirilebileceği sonucuna varılmıştır.

Anahtar Kelimeler: Elektrokoagülasyon, Bira endüstrisi atıksuları, elektrot materyali, hibrit bağlantı şekli, kimyasal oksijen ihtiyacı, bulanıklık, işletme maliyeti

\section{Treatment of Brewing Wastewater by Electrocoagulation and Effect of Hybrid Electrode Connection}

\author{
${ }^{1}$ Murat Eyvaz \\ ${ }^{1}$ Gebze Technical University, Department of Environmental Engineering, 41400, Gebze-Kocaeli, Turkey, \\ meyvaz@gtu.edu.tr
}

\begin{abstract}
In this study, an EC process composed of the different anode and cathode materials was used for the treatment of brewery wastewater and the treatment performance and operating cost were analyzed. Iron $(\mathrm{Fe})$ and aluminum (Al) electrodes are arranged in eight different anode-cathode-anode-cathode (A-C-A-C) combinations (Al-Al-Al-Al, Fe-Fe-Fe-Fe, Al-Fe-Fe-Fe, Al-Fe-Fe$\mathrm{Al}, \mathrm{Al}-\mathrm{Fe}-\mathrm{Al}-\mathrm{Fe}, \mathrm{Fe}-\mathrm{Al}-\mathrm{Al}-\mathrm{Al}, \mathrm{Fe}-\mathrm{Al}-\mathrm{Al}-\mathrm{Fe}, \mathrm{Fe}-\mathrm{Al}-\mathrm{Fe}-\mathrm{Al}$ ) and the effects of $\mathrm{pH}$, current density and electrolysis time on COD and turbidity removal efficiencies and operating costs were investigated. At the end of the study, at the optimum EC conditions (pH 7, current density: $60 \mathrm{~A} / \mathrm{m}^{2}$ and electrolysis time: $30 \mathrm{~min}$ ) COD and turbidity removal efficiencies were $80 \%$ and $92 \%$, respectively, for iron electrodes $(\mathrm{Fe}-\mathrm{Fe}-\mathrm{Fe}-\mathrm{Fe})$ and $91 \%$ and $97 \%$ for $\mathrm{EC}$ reactor with iron-aluminum hybrid (Fe-Al-Fe-Al) electrodes. The operating cost of one cubic meter of beer industry wastewater treatment with EC under the optimum conditions was calculated as $\sim 35 \mathrm{TL}$ and the cost of one $\mathrm{kg}$ COD removal was calculated as $\sim 12 \mathrm{TL}$. Considering the effluent characteristics, in future studies it can be concluded that the hybrid electrode-EC system can be used as a pre-treatment method for similar industrial wastewaters and can be integrated with an anaerobic process that can reduce high COD concentrations or can be considered as the final treatment for the treatment of effluent following an oxidation process.
\end{abstract}

Keywords: Electrocoagulation, brewery wastewaters, electrode material, hybrid connection type, chemical oxygen demand, turbidity, operating cost 


\section{GÍRİş}

Bira endüstrisi büyük miktarlarda su tüketen endüstrilerden biridir [1] ve tipik olarak litre bira üretimi başına 3-10 litre atık su üretir [2]. Atık su, büyük miktarda protein, yağ, lif, karbonhidrat, maya, şerbet artığı, [3] etanol, uçucu yağ asitleri ve toplam askıda katı madde (TAKM) içerir [4]. Bira üretiminin ana kaynakları, şişe dolumu, temizleme ve tank boşaltma gibi proses adımlarından kaynaklanmaktadır [5]. Arıtma işlemi görmemiş bira atıksuyunun tipik özellikleri; KOİ: $2000-6000 \mathrm{mg} / \mathrm{L}$, BOİ: $1200-3600 \mathrm{mg} / \mathrm{L}$, TAKM: 200-1000 mg/L, TN: 25-80, TP: 10-50 mg/L, sicaklık: 18 $40{ }^{\circ} \mathrm{C}$ ve $\mathrm{pH}: 3-12$ şeklindedir [6]. Bira fabrikalarının atıksularındaki organik bileşenler genellikle toksik olmayıp şeker, nişasta ve proteinden oluşmaktadır. Ancak yüksek organik madde içeriği yüksek kimyasal oksijen ihtiyacı (KOİ) gerektirmektedir [7]. Arıtılmamış ya da yetersiz arıtılmış bira üretim atıksularının deşarjı, hem yüzey hem de yeraltı sularında oksijen tüketimine neden olmakta, çevre ve canlılar için tehdit oluşturmaktadır [2 ve 6]. Bu nedenle, yüksek organik içerikli atık sular arıtılmadan kanalizasyona ve yüzeysel su kütlelerine deşarj edilmemelidir [8, 9]. Ayrıca, mayalanma işleminin gerektirdiği yüksek su ihtiyacı nedeniyle, arıtılmış bira atıksuyunun yeniden kullanılması da çok önemlidir ve arıtılan atık su, temizlik, sulama işlemleri ve diğer çeşitli genel amaçlarla alternatif olarak değerlendirilebilir [10]. Bu amaçla literatürde birçok yöntem bulunmakta ve bunların bazıları arıtma işlemleri olarak kullanılırken diğerleri geri kazanım/yeniden kullanım süreçleri olarak tercih edilmektedir. Bütün bu yöntemler arıtma çıkış suyunun kullanım amacına veya su kalitesine bağlı olarak seçilmektedir [2].

Bira endüstrisi atıksularının arıtımında kullanılan koagülasyon ve çöktürme proseslerinin KOİ gideriminde yetersiz kaldığı rapor edilmektedir [2]. Membran biyoreaktör sistemleri ise arıtmada daha etkili iken, yüksek yatırım maliyeti ve membran kirlenmesi bu metodun dezavantajları arasında yer almaktadır [11]. Havalandırmalı biyolojik sistemler ise yüksek enerji tüketimi ve çamur uzaklaştırma maliyetleri sebebiyle tek başına bir arıtım yöntemi olarak bira endüstrisi atıksularının arıtımında artık kullanılmamaktadır [12]. Bahsedilen dezavantajları ortadan kaldırmak için bazı yeni yöntemler tek başına veya mevcut yöntemler ardışık olarak kullanılmaktadır. Şu anda, bira atıksularının arıtılmasında bireysel veya ardışık olarak kullanılan yöntemlere örnek olarak, koagülasyonflokülasyon [13], MBR [11]; yukarı akışlı anaerobik çamur battaniyesi (UASB) [14-16], nanofiltrasyon ve ters osmoz [4, 17] gösterilebilir. $\mathrm{Bu}$ yöntemler dışında, atık su arıtımında EC yaygın olarak tercih edilmektedir, çünkü basit, güvenilir ve ekonomik bir prosestir [18]. Ayrıca, EC ek kimyasallar gerektirmez ve dolayısıyla ikincil kirliliğe ve yüksek çamur hacimlerine neden olmaz [19]. EC, atık suya daldırılmış çözünebilir metal elektrotlar arasında doğru akım (DC) kullanarak metal hidroksitler oluşturur ve bu metal hidroksitler inorganik ve organik kirleticiler ile patojenlerin uzaklaştırılması için koagülan ve/veya adsorban görevi görür [20]. Ayrıca, önceden oluşturulmuş hidroksitler yerine, arıtma sırasında oluşturulmuş (in situ) hidroksitler ile daha fazla adsorpsiyon kapasitesi sağlandığ EC prosesi bütün bu avantajları sebebiyle farklı karakteristiklerde pek çok evsel ve endüstriyel atıksuyun arıtımında başarıyla uygulanmıştır [21-24]. Ayrıca, bu çalışmanın kapsamı olan bira endüstrisi atıksularına benzer tarım ve gıda endüstrilerinin atık sularının arıtılması için de EC prosesi tercih edilmiştir [25-30]. Ancak, bira/mayalama prosesi atıksularının arıtılması konusunda EC ile ilgili nispeten az sayıda çalışma bulunmaktadır. Ayrıca, iki farklı elektrot materyalinin aynı EC reaktörü içerisinde farklı anotkatot dizilimlerinde kullanıldığı az sayıda bazı çalışmalar da yürütülmüş, anotun farklı katotun farklı metalden oluşturulduğu EC prosesinin, arıtma verimlerini artırdığı rapor edilmiştir [31-33]. Yine bu çalışmaların çoğunda ekonomik analiz de yapılmamıştır. $\mathrm{Bu}$ nedenle, bu çalışmanın amacı, model elektrolitik çözelti olarak seçilen bira fabrikası atıksularının EC yöntemi ile arıtımının teknik ve ekonomik fizibilitesini belirlemek ve EC reaktörü içerisinde kullanılan dört adet elektrotun farklı dizilimlerinin ve anot/katot materyallerinin proses performansina etkisini değerlendirmektir.

\subsection{Elektrokoagülasyon Hakkında Özet Bilgiler}

EC, konvansiyonel koagülasyona benzer bir fiziko-kimyasal işlem olup, metal hidroksitler oluşturmak için elektrik akımı kullanır. Bir reaktör içerisindeki elektrolitik çözeltiye (atıksu) batırılmış elektrotların (genellikle demir ve alüminyum gibi çözünen metaller) aktif yüzeyleri arasında iyon transferinin meydana geldiği bir elektrik alanı üretmek için genellikle DC güç kaynağı çalıştırılır. EC'nin arıtma işlemi üç aşamaya ayrılabilir: Birincisi, çözünen elektrotlar, elektrolitik oksidasyon ile koagülanları oluşturur; ikincisi, koagülanlar kirletici maddeleri destabilize eder ve üçüncü olarak da destabilize olmuş kirletici maddeler, partiküler süspansiyonlar ve emülsiyonların kırılması ile bir kaç adımdan oluşan reaksiyonlarla flokları oluşturur: (i) Yüklü türler etrafındaki dağınık çift tabakanın, anodun oksidasyonu ile oluşan iyonların etkileşimleri ile sıkıştırılması, (ii) Atıksuda bulunan iyonik türlerin, anodun elektrokimyasal çözünmesiyle üretilen zıt yüklü iyonlar tarafindan nötrleştirilmesi. $\mathrm{Bu}$ zit yüklü iyonlar, elektrostatik parçacıklar arasındaki itme kuvvetlerini van der Waals çekiminin baskın olduğu ölçüde azaltır ve böylece birbirine yaklaşan parçacıklar koagüle olurlar. (iii) Koagülasyon sonucu oluşan çamur battaniyesi de sulu ortamda (atıksuda) kalan diğer kolloidal parçacıkları tutarak ve aralarında köprüler oluşturarak flokları meydana getirir [20].

EC prosenin arıtma performansını etkileyen parametreler; çözeltinin pH'1, akım yoğunluğu, güç kaynağının tipi, elektroliz süresi, çözeltinin iletkenliği, elektrotların bağlantı şekli (seri/paralel), elektrotlar arası mesafe, elektrotun fiziksel şekli, giderilmek istenen kirleticinin başlangıç konsantrasyonu, elektrolit çözeltinin (gerektiğinde) iletkenliğini sağlamak için katılan tuzun cinsi, karıştırma (yapılıyorsa) hızı ve elektrot materyali şeklinde sinıflandırılabilir [26]. Demir veya alüminyum elektrotlar 
kullanıldığında, genel olarak anotların ve katotların tamamı ya demir ya da alüminyum materyali olarak seçilmektedir. Son yıllarda elektrot materyali üzerine yürütülen araştırmalarda alaşım elektrotlar ve anot ile katotun farklı malzemelerden dizayn edildiği EC reaktörleri üzerine de çalışmalar gerçekleştirilmektedir. Bu çalışma kapsamında da demir ve alüminyumların aynı anda reaktör içerisinde yer aldığı bir EC reaktörünün bir endüstriyel atıksu arıtımındaki performansı araştırılmıştır.

\section{MATERYAL VE METOT}

\subsection{Bira Endüstrisi Atıksuyunun Karakteristiği}

Bu çalışmada kullanılan atık su, günde yaklaşık 3000 m3 atıksu üreten bir bira fabrikasından alınmıştır. Atıksuyun özellikleri pH: 7.0 $\pm 0,3$, KOİ: $3620 \pm 90 \mathrm{mg} / \mathrm{L}$, BOİ5: 2140 $\pm 55 \mathrm{mg} / \mathrm{L}$, TAKM: $1213 \pm 46 \mathrm{mg} / \mathrm{L}, \mathrm{TN}: 79 \pm 6 \mathrm{mg} / \mathrm{L}, \mathrm{TP}:$ $25 \pm 4$ mg/L, Renk: $4902 \pm 170$ Pt-Co, Bulanıklık: $1554 \pm 88$ NTU ve İletkenlik: $3301 \pm 141 \mu \mathrm{S} / \mathrm{cm}$ olarak ölçülmüştür.

\subsection{EC Reaktörünün Özellikleri}

EC reaktörü olarak $13 \times 13 \times 12 \mathrm{~cm}$ boyutlarında bir pleksiglas tank kullanılmıştır. Toplam $143 \mathrm{~cm} 2$ aktif elektron transferi alanına sahip dört adet demir ve/veya alüminyum elektrot atıksu içerisine tamamen daldırılmış ve aralarında 20'şer mm mesafe ayarlanmıştır. Elektrotlar, monopolar paralel (MP-P) modda bir dijital DC güç kaynağına (Maksimel, Ankara, Türkiye) bağlanmıştır. Seri bağlantılı elektrotlar ile mukayese edildiğinde aynı sabit akımda daha düşük bir hücre potansiyeli gerektirmesi sebebiyle MP-P bağlantı şekli tercih edilmiştir. Voltajın düşük olması da işletme maliyetini azaltacaktır. MP-P EC reaktörü, Şekil 1'de şematik olarak gösterilmiştir.

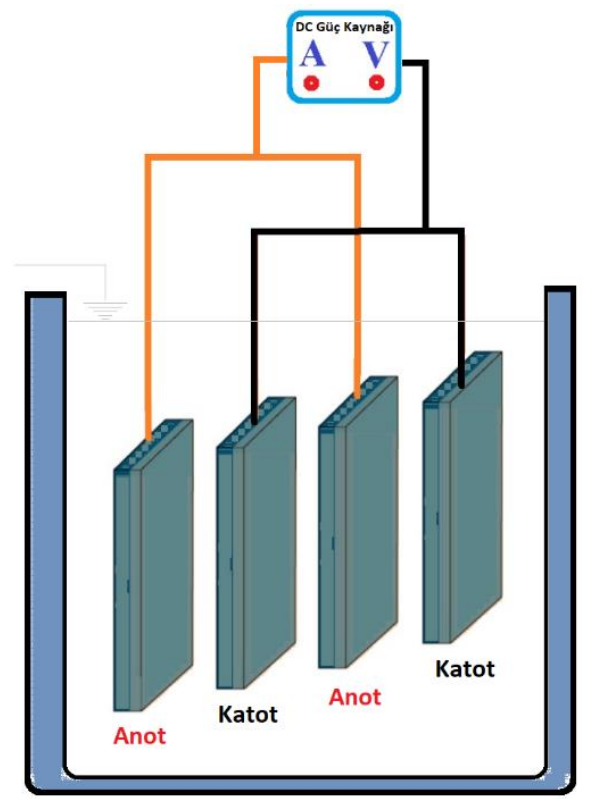

Şekil 1. Çalışmada kullanılan EC reaktörünün şematik gösterimi

\subsection{Deney Prosedürü}

Her çalışmada, reaktöre 1,5 L atıksu konulup, homojen bir elektrolitik çözelti elde etmek, iyon transferini iyileştirmek ve koagülasyona yardımcı olmak amacıyla atıksu manyetik bir karıştırıcı (250 rpm, Velp Are) ile her deney süresince karıştırılmıştır. Çalışma kapsamındaki akım yoğunluklarına ulaşmak için gereken sabit akım, atık suyun kendi iletkenliği yardımıyla elde edilebildiğinden, ayrıca atıksuya herhangi bir tuz ilave edilmemiştir. Atıksu iletkenliği ve $\mathrm{pH}^{\prime} 1$ multimetre ile ölçülmüştür (Hach Lange HQ40d-Düsseldorf, Almanya). $\mathrm{pH}$ deneylerinde, atıksu başlangıç $\mathrm{pH}$ 'ını ayarlamak için $\mathrm{NaOH}$ (Merck-Darmstadt, Almanya) ya da H2SO4 (Merck-Darmstadt, Almanya) kullanılmıştır. İstenen akım yoğunluğuna karşılık gelen akım, her deneyin başında gerekli değere sabitlenmiştir. EC, kesikli modda işletilerek, her deneyden sonra elektrot yüzeylerindeki katı kalıntıları gidermek için elektrotlar, $100 \mathrm{ml} \mathrm{HC1}(\%$ 36,5) ile $200 \mathrm{ml}$ hekzametilentetramin sulu çözeltisinin $\left(\begin{array}{llll}\% & 2,80) & \text { [34] }\end{array}\right.$ karışımından hazırlanan bir çözelti içinde 1-2 dak., bekletilmiş ve sonrasında demineralize su ile yıkanıp kurutulduktan sonra elektrot tüketiminin hesaplanması için tartılmıştır. Her deney sonunda atıksubir filtere kağıdından (Whatman 40 ashless-NJ, ABD) süzülmüş ve süzüntü analiz edilmiştir. Her özel çalışma koşuluna ait çamur miktarları, filtre kağıdında kurutulmuş katı maddelerin tartılmasıyla hesaplanmıştır. Her deney üç defa tekrarlanmış ve ortalama ile standart sapmalar hesaplanarak grafiklerde verilmiştir. Toplam işletme maliyetlerinin değerlendirilmesinde kullanılan ekonomik veriler, Tablo 1'de verilmiştir.

Tablo 1. İşletme maliyetinin hesaplanmasında kullanılan ekonomik parametreler (2019 yılının ikinci çeyreği itibariyle Türkiye için).

\begin{tabular}{|l|c|}
\hline \multicolumn{1}{|c|}{ Öğe } & Birim Fiyat \\
\hline Demir elektrot (TL/kg) & 3,13 \\
\hline Alüminyum elektrot (TL/kg) & 23,0 \\
\hline $\begin{array}{l}\text { Kimyasallar (asit, baz, vb) } \\
\left(\mathrm{TL} / \mathrm{m}^{3}\right)\end{array}$ & 0,3 \\
\hline Elektrik (TL/kWh) & 0,42 \\
\hline $\begin{array}{l}\text { Bakım, onarım ve amortisman } \\
\left(\mathrm{TL} / \mathrm{m}^{3}\right)^{*}\end{array}$ & 0,1 \\
\hline İşçilik/personel (TL/m $\left.{ }^{3}\right)^{* *}$ & 1,2 \\
\hline Çamur bertarafı $(\mathrm{TL} / \mathrm{kg})^{* * *}$ & 0,12 \\
\hline
\end{tabular}

* $500 \mathrm{~m}^{3} /$ gün kapasiteli ve 10 y1l kullanım ömrüne sahip endüstriyel ölçekte bir EC tesisi için verilmiştir.

** Tesiste günlük 120 TL yevmiye ile beş işçinin çalıştığı kabul edilmiştir.

*** 10 ton çamur taşıma kapasiteli kamyonun 20 km mesafe için $1000 \mathrm{TL}$ günlük kiralama bedeli dikkate alınmıştır.

Bütün analitik ölçümler standart metotlara [35] göre gerçekleştirilmiş ve kirletici giderme verimleri aşağıdaki eşitlik yardımıyla hesaplanmıştır: 
Kirletici Giderme Verimi $(\%)=\frac{C_{0}-C}{C_{0}} \times 100$

Burada C, KOİ, bulanıklık, renk, TAKM, TP ve TN parametrelerinin EC çıkış suyu konsantrasyonu $(\mathrm{mg} / \mathrm{L}$ veya NTU) olup, $\mathrm{C}_{0}$ ise atıksudaki başlangıç konsantrasyonunu (mg/L veya NTU) temsil etmektedir. Işletme maliyetinin ana unsurları olan elektrot ve enerji tüketimleri asağıdaki eşitlikler yardımıyla bulunmuştur:

$C_{\text {elektrot }}\left(\mathrm{kg} / \mathrm{m}^{3}\right)=\frac{M_{w} \times i \times t}{F \times z \times v}$

$C_{\text {enerji }}\left(k W h / m^{3}\right)=\frac{V \times i \times t}{v}$

Burada V: ortalama hücre voltaj1 (volt), i: uygulanan akım (amper), t: elektroliz süresi (saat), v: atıksu hacmi $\left(\mathrm{m}^{3}\right), \mathrm{Mw}$ : molekül ağırlığı (Fe ve Al elektrotları için sırasıyla 55,86 ve 26,98 g/mol), F: Faraday sabiti (96485 C/mol) ve z: işlemde yer alan elektronların sayısıdır (Fe için 2 ve $\mathrm{Al}$ için 3$)$.

\section{TARTIŞMA VE SONUÇ}

EC sürecinin performansını etkileyen birçok işletme parametresi olup, her bir parametrenin proses performans üzerindeki belirli etkileri literatürdeki çalışmalarda bulunabilir. Bu çalışmada, bira fabrikası atıksuyunun $\mathrm{pH}$ değeri, akım yoğunluğu, elektroliz süresi ve özellikle güç kaynağı tipi (DC veya ACP) gibi ana parametreler incelenmiştir.

\subsection{Anot-Katot Materyali ve Bağlantı Türünün Etkisi}

EC reaktöründe metal hidroksit türlerini oluşturabilmek için, elektrotlarda çözünme sonucu açığa çıkan yeterli miktarda metal iyonlarının sulu çözeltiye geçmesi gerekmektedir. Elektrotlara gereken akımı uygulamak için makul bir elektroliz süresi sağlanmalıdır. Farklı anot katot çiftlerinin EC verimlerinin ölçülmesi için $\mathrm{pH}(7)$ ve akım yoğunluğu $(60 \mathrm{~A} / \mathrm{m} 2)$ parametreleri sabit tutularak, elektroliz süresi değiştirilmiştir. Anot ve katot materyallerinin değiştirilerek sekiz farklı elektrot bağlantısı gerçekleştirilerek 7,5 ile 60 dakika aralığında sekiz işletme süresi denenmiştir. Farklı işletme sürelerinde anot-katot türünün KOİ ve bulanıklık giderme verimine etkisi Şekil 2'de gösterilmektedir. Şekilden görüldüğü gibi, 22,5 dakikalık elektroliz süresine kadar bütün bağlantı türlerinde hem KOİ hem de bulanıklık giderme verimleri hızlı bir biçimde artmış, daha yüksek elektroliz sürelerinde hemen hemen değişkenlik göstermemiştir. $\mathrm{Bu}$ durum, belli bir elektroliz süresinde atıksudaki kirleticilerin giderilmesi için reaktörde yeterli sayıda flok oluşumuna ulaşılmış olduğu sonucu ile açıklanabilir [36]. Ayrıca, elektroliz süresinin artmasıyla hem anodik pasifizasyon hem de katodik polarizasyona bağlı olarak kirletici gideriminin zamanla artmadığı da düşünülebilir [37, 38].
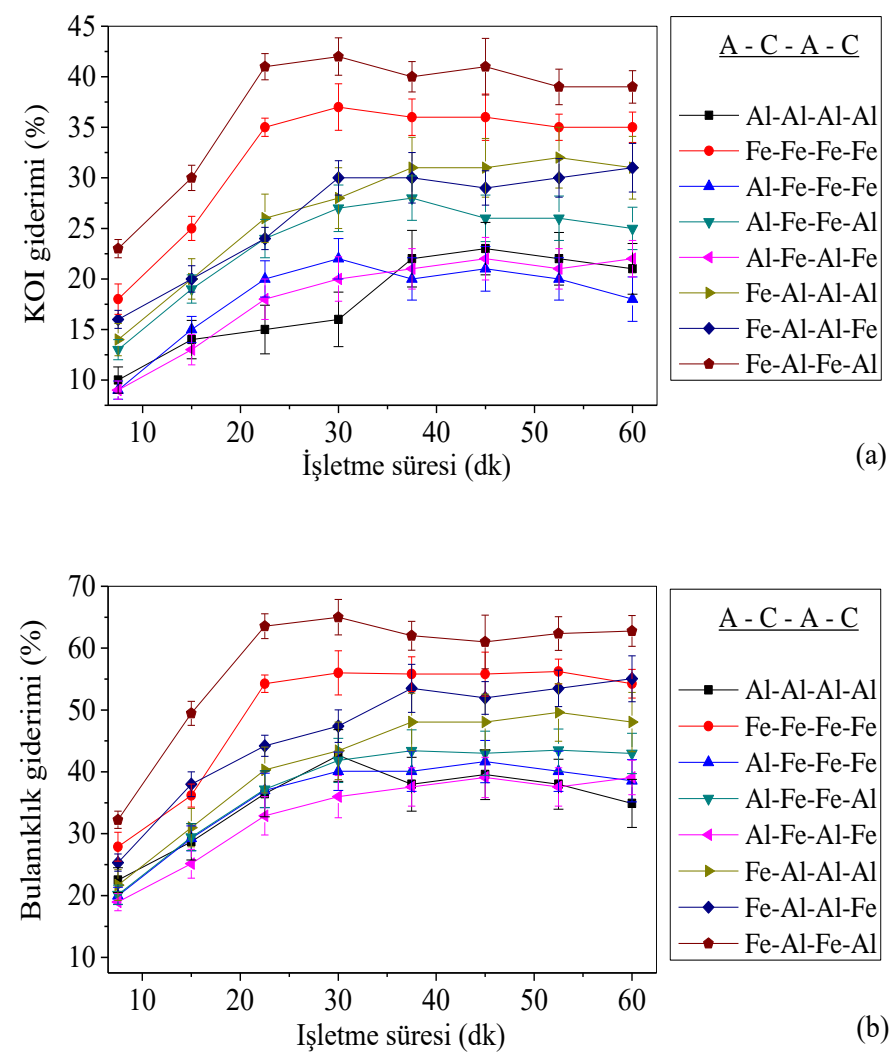

Şekil 2. Anot-katot materyali ve elektrot dizilimin (a) KOİ ve ( b) bulanıklık giderimlerine etkisinin zamanla değişimi (pH: 7, A.Y.: $60 \mathrm{~A} / \mathrm{m}^{2}$ )

KOİ ve bulanıklık gideriminde en yüksek verimlerin, anotların demir, katotların ise alüminyum materyali olarak uygulandığ1 reaktörde gerçekleştiği görülmüştür. $\mathrm{Bu}$ bağlantı tipinde maksimum KOİ ve bulanıklı giderimleri (30 dakikalık elektroliz süresinde) sirasıyla $\% 42$ ve $\% 65$ olurken, sekiz bağlantı tipi arasında en yüksek ikinci giderme verimlerini sağlayan ve hem anot hem de katot olarak demir metalinin kullanıldığ1 reaktörde ise \% 37 ve 56 olmuştur. Sadece alüminyum elektrotlar kullanıldığında ise aynı işletme süresinde giderme verimleri $\% 16$ ve $\% 43$ olarak elde edilmiştir. Bu deneylerden maksimum kirletici giderme verimlerinin elde edildiği 30 dakikalık elektroliz süresi ve en yüksek giderme verimlerinin elde edildiği $\mathrm{Fe}-\mathrm{Al}-\mathrm{Fe}-\mathrm{Al}$ ile $\mathrm{Fe}-\mathrm{Fe}-\mathrm{Fe}-\mathrm{Fe}$ bağlantı şekilleri seçilmiş ve takip eden $\mathrm{pH}$ ve akım yoğunluğu deneyleri bu elektrot dizilimleri ile gerçekleştirilmiştir. Seçilen iki bağlantı şeklinin işletme maliyetleri de Şekil 3'de grafiğge geçirilmiş böylece hibrit bağlantının etkisi daha net mukayese edilebilmiştir. Arıtılan bir metreküp bira fabrikası atıksuyunun işletme maliyetleri demir elektrotlar ve hibrit bağlantılı elektrotlar ile oldukça yakın elde edilmiş ve sırasıyla 18,27 ve 19,28 TL olarak hesaplanmıştır. 


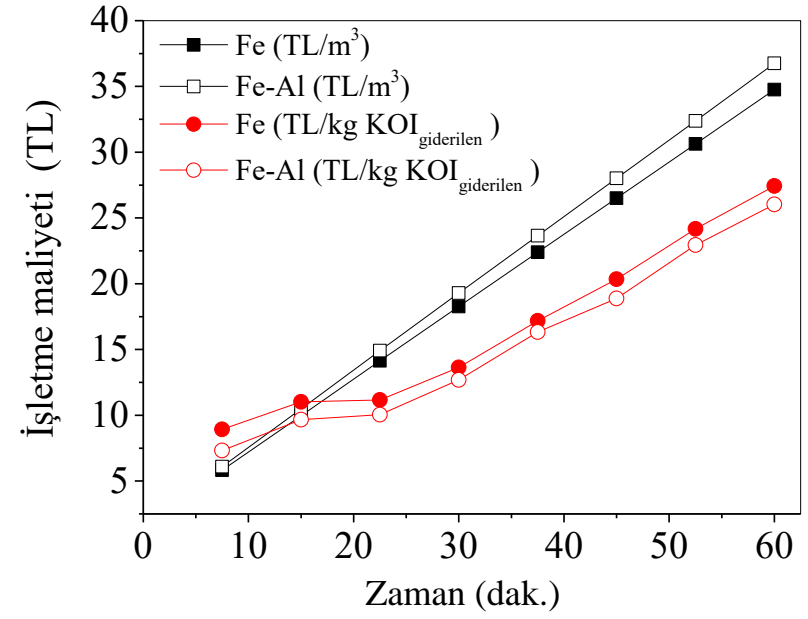

Şekil 3. Anot-katot materyali ve elektrot dizilimin işletme maliyetlerine etkisinin zamanla değişimi (pH: 7, A.Y.: 60 $\mathrm{A} / \mathrm{m}^{2}$ )

\section{2. $\mathrm{pH}$ etkisi}

Çözeltinin başlangıçtaki pH değeri, EC sürecinin performansını büyük ölçüde etkilemektedir [19]. Demir elektrot bir EC reaktöründe anot olarak kullanıldığında, demir hidroksit, $\mathrm{Fe}(\mathrm{OH}) \mathrm{n}$ üretir, burada $\mathrm{n}=2$ veya 3 'tür [39]. Demir hidroksit iki mekanizma ile üretilmektedir [40]:

\section{Mekanizma}

Anot:

$2 \mathrm{Fe} \rightarrow 2 \mathrm{Fe}^{2+}+4 \mathrm{e}^{-}$

$2 \mathrm{Fe}^{2+}+5 \mathrm{H}_{2} \mathrm{O}+1 / 2 \mathrm{O}_{2} \rightarrow 2 \mathrm{Fe}(\mathrm{OH})_{3(\mathrm{~s})}+4 \mathrm{H}^{+}$

Katot:

$4 \mathrm{H}_{2} \mathrm{O}+2 \mathrm{e}^{-} \rightarrow 4 \mathrm{OH}^{-}+2 \mathrm{H}_{2(\mathrm{~g})}$

Tam reaksiyon:

$2 \mathrm{Fe}+5 \mathrm{H}_{2} \mathrm{O}+1 / 2 \mathrm{O}_{2} \rightarrow 2 \mathrm{Fe}(\mathrm{OH})_{3(\mathrm{~s})}+4 \mathrm{H}_{2(\mathrm{~g})}$

\section{Mekanizma}

Anot:

$\mathrm{Fe} \rightarrow \mathrm{Fe}^{2+}+2 \mathrm{e}^{-}$

$\mathrm{Fe}^{2+}+2 \mathrm{OH}^{-} \rightarrow \mathrm{Fe}(\mathrm{OH})_{2(\mathrm{~s})}$

Katot:

$2 \mathrm{H}_{2} \mathrm{O}+2 \mathrm{e}^{-} \rightarrow \mathrm{H}_{2}+2 \mathrm{OH}^{-}$

Tam reaksiyon:

$\mathrm{Fe}+2 \mathrm{H}_{2} \mathrm{O} \rightarrow \mathrm{Fe}(\mathrm{OH})_{2(\mathrm{~s})}+\mathrm{H}_{2(\mathrm{~g})}$

Demir elektrotlar kullanıldığında optimum flok oluşumu için en iyi $\mathrm{pH}$ aralığ deneylerinde alüminyum elektrotlar sadece katot olarak kullanılacağından aşağıdaki katot reaksiyonları gerçekleşecektir $[42,43]$. Katot materyalinin anottaki gibi yüksek miktarda çözünmeyeceği dikkate alınırsa, kirletici gideriminde rol oynayan hidroksit bileşiklerinin başlıca demir hidroksit olduğu söylenebilir.

Katot:

$3 \mathrm{H}_{2} \mathrm{O}+3 \mathrm{e}^{-} \rightarrow 3 \mathrm{OH}^{-}+3 / 2 \mathrm{H}_{2(\mathrm{~g})}$

Tam reaksiyon:

$2 \mathrm{Al}+6 \mathrm{H}_{2} \mathrm{O}+2 \mathrm{OH}-\rightarrow 2 \mathrm{Al}(\mathrm{OH})^{-4}+3 \mathrm{H}_{2(\mathrm{~g})}$

Her iki elektrot bağlantı şekli için maksimum kirletici giderme veriminin ve minimum işletme maliyetinin elde edildiği optimum $\mathrm{pH}$ değerini araştırmak için on bir $\mathrm{pH}$ değeri (4 - 4,5 - 5-5,5 - 6 - 6,5 - 7 - 7,5 - 8 ve 8,5) seçilmiştir. Akım yoğunluğu ve elektroliz süresi parametreleri sabit tutularak sirasıyla $60 \mathrm{~A} / \mathrm{m}^{2}$ ve 30 dakika olarak ayarlanmıştır. Başlangıç pH'ının KOİ ve bulanıklık giderme verimleri üzerindeki etkileri Şekil 4'te gösterilmiştir. Kirletici giderme verimleri atıksuyun (elektrolitik çözelti) başlangıç pH'ına güçlü bir şekilde bağlıdır, çünkü metal hidroksitlerin meydana geldiği optimum pH'ta, askıda kalan parçacıkların destabilizasyonu ve agregasyonu meydana gelmektedir.
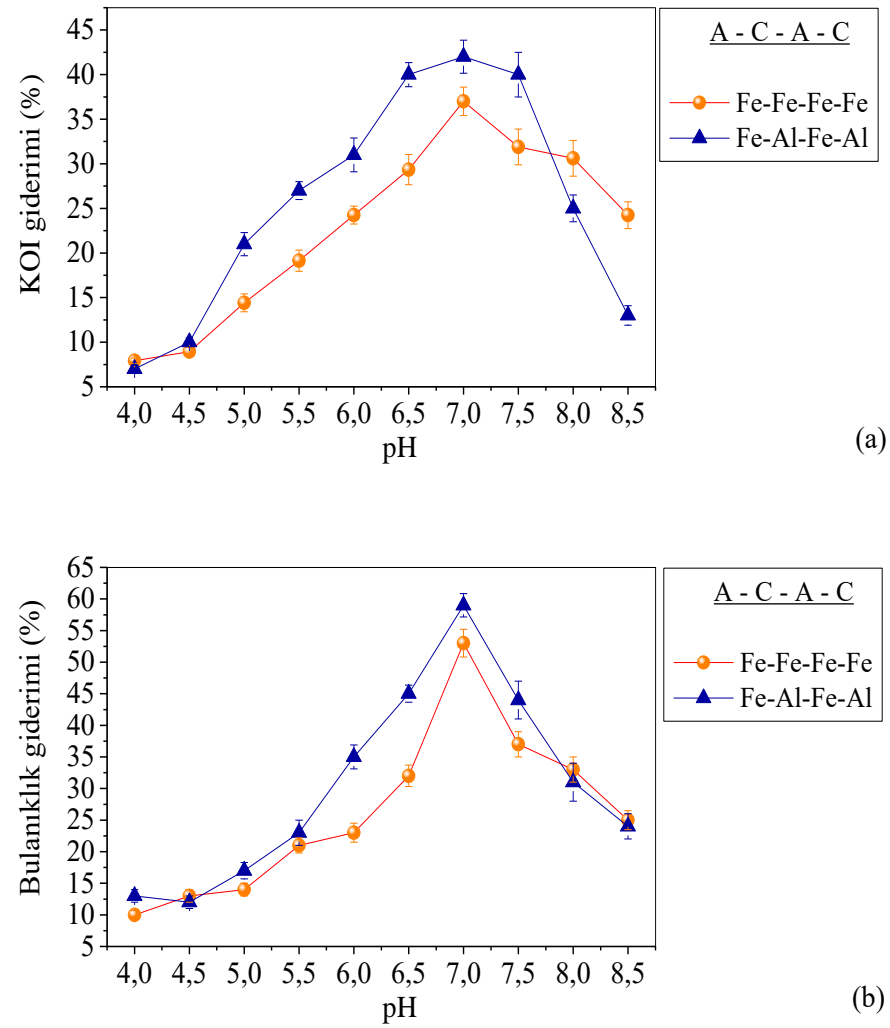

Şekil 4. pH'nın (a) KOİ ve (b) bulanıklık giderimlerine etkisi (elektroliz süresi 30 dak., A.Y.: $60 \mathrm{~A} / \mathrm{m}^{2}$ )

Şekil 4'te görüldüğü gibi, her iki elektrot bağlantı şeklinin malzemesinin hem KOİ hem de bulanıklı giderme eğilimleri benzerlik göstermektedir. Maksimum giderme verimlerine her iki grafikte de $\mathrm{pH} 7$ değerinde ulaşıldığ görülmektedir. Her iki bağlantı türünde de anot materyali olarak demir elektrotlar kullanıldığından, anodik 
çözünmenin esas olarak kolloidal parçacıkları destabilize eden metal iyonlarını bu $\mathrm{pH}$ değerinde ürettiği sonucuna varılabilir. Metal iyonlarının ayrıca hidroksit formunda çöktüğü bu pH değerinde organik kirleticilerle tepkimeye girerek adsorpsiyonla birlikte çökeltme ile de kirleticileri uzaklaştırdığı söylenebilir [44]. Hibrit bağlantı şekli ile KOİ gideriminde $\% 42$ ve sadece demir elektrotların kullanıldığ bağlantı şeklinde ise $\% 37$ giderme verimi elde edilmiştir.

Başlangıç pH değerinin işletme maliyetlerine etkisi de Şekil 5'de sunulmuştur. Arıtılan birim atıksu hacmi başına gerçekleşen işletme maliyetinin başlangıç pH'sından etkilenmediği söylenebilir. Çünkü işletme maliyetinin en büyük kısmını oluşturan elektrot tüketimi ve enerji maliyetleri doğrudan işletme süresi ve uygulanan elektrik akımı ile ilişkilidir. Her bir farklı $\mathrm{pH}$ deneyinde akım yoğunluğu ve elektroliz süresi sabit tutulduğundan arıtılan m3 atıksu hacmi başına işletme maliyeti değişkenlik göstermemiştir. Ancak giderilen birim KOİ için elde edilen işletme maliyetleri her $\mathrm{pH}$ değerinde değişkenlik göstermiş ve beklendiği gibi maksimum giderme veriminin elde edildiği pH 7 değerinde minimum olmuştur (Fe elektrotlar için 13,64 TL ve Fe-Al hibrit bağlantı için 12,69 TL). Aşağıdaki akım yoğunluğunun etkisinin belirlendiği deneylerde optimum olarak bulunan $\mathrm{pH} 7$ seçilmiştir. Ayrıca atıksuyun kendi $\mathrm{pH}$ değerinin de $\sim 7$ olması, EC prosesi için yeniden bir $\mathrm{pH}$ ayarlaması gerektirmeyecek ve kimyasal maliyetlerini azaltacaktır.

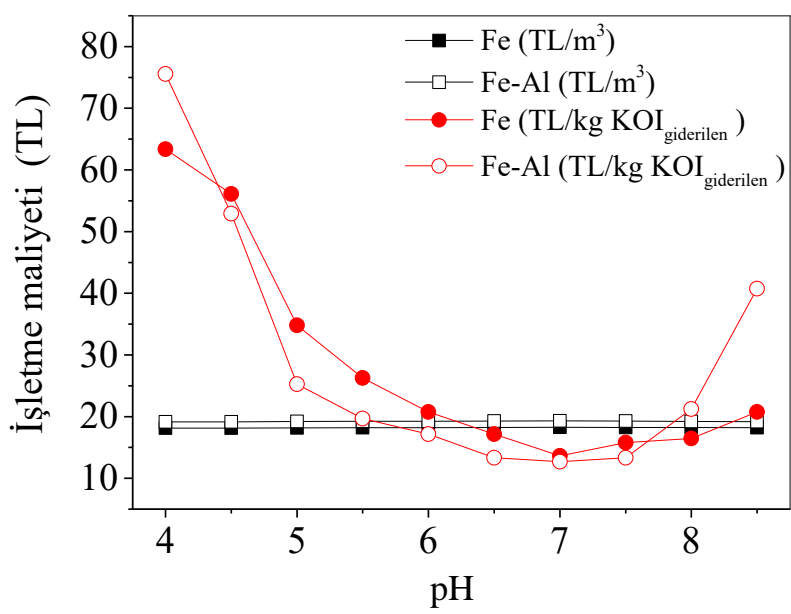

Şekil 5. pH'nın işletme maliyetlerine etkisi (elektroliz süresi 30 dak., A.Y.: $60 \mathrm{~A} / \mathrm{m}^{2}$ )

\subsection{Akım Yoğunluğunun Etkisi}

Uygulanan akımın dolayısıyla akım yoğunluğunun büyüklüğü elektrotlardan salınan metal iyonlarının miktarını ve metal hidroksit oluşum oranını belirlemektedir [45]. Akım yoğunluğu aynı zamanda flotasyona yardımcı olabilecek kabarcık üretiminin oranını, büyüklüğünü ve flokların büyümesini de doğrudan etkiler $[19,45]$. Bununla beraber, akım yoğunluğu arttıkça, enerji ve elektrot maliyeti de artacağı gibi, yüksek akım yoğunluklarında katot materyalinde meydana gelen pasivizasyon sebebiyle kirletici gideriminde de verim düşüşü gözlenebilmektedir [25].
Ayrica katot pasivizasyonu EC hücresinin potansiyelini yükselterek enerji ihtiyacını da artırmaktadır [26]. Bu nedenle, akım yoğunluğu optimize edilmelidir. Bütün akım yoğunluğu deneylerinde, $\mathrm{pH}$ deneylerinden seçilen $\mathrm{pH} 7$ değeri ve zaman deneylerinden seçilen 30 dakikalık elektroliz süresi uygulanarak $\mathrm{pH}$ ve işletme süresi sabit tutulmuştur. Akım yoğunluğu ise 30 ve $240 \mathrm{~A} / \mathrm{m}^{2}$ aralığında sekiz farklı değerde uygulanmıştır. Akım yoğunluğunun KOİ ve bulanıklık giderme verimleri üzerine etkisi Şekil 6'da gösterilmiştir. Her iki elektrot uygulama biçiminde de giderme verimleri $120 \mathrm{~A} / \mathrm{m}^{2}$ değerine kadar hızlı bir şekilde artmakta, daha yüksek akım yoğunluklarında ise sabit kalma ya da azalma eğilimindedir. Bu akım yoğunluğunda KOİ ve bulanıklık giderme verimleri demir elektrotlar kullanıldığında sırasıyla \%80 ve \%92 olurken, demiralüminyum hibrit bağlantılı EC reaktöründe ise $\% 91$ ve $\% 97$ olarak gerçekleşmiştir.
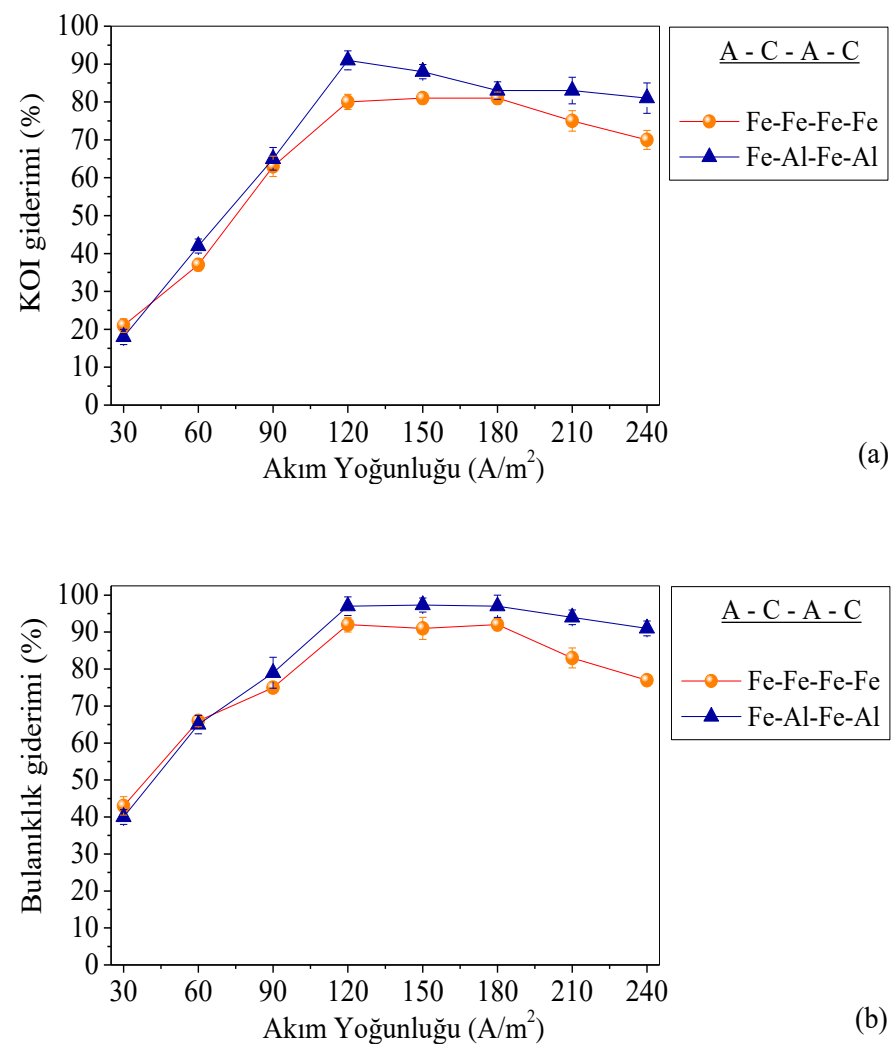

Şekil 6. Akım yoğunluğunun (a) KOİ ve (b) bulanıklık giderimlerine etkisi (pH: 7., elektroliz süresi: 30 dak.)

Enerji ve elektrot tüketimi, çamur oluşumu ve işletme maliyeti, akım yoğunluğuna büyük ölçüde bağlıdır. Akım yoğunluğunun EC prosesinin işletme maliyetine etkisi Şekil 7'de grafiğe geçirilmiştir. KOİ ve bulanıklık giderme verimlerinin maksimum olduğu $120 \mathrm{~A} / \mathrm{m} 2$ değerinde $1 \mathrm{~m}^{3}$ bira endüstrisi atıksuyunun seçilen deneysel şartlar altında EC ile arıtımının işletme maliyeti $\sim 35$ TL olarak bulunurken, $1 \mathrm{~kg}$ KOİ gideriminin maliyeti ise $\sim 12 \mathrm{TL}$ olarak hesaplanmıştır. Optimum deney şartlarında Fe-Fe-Fe-Fe ve $\mathrm{Fe}-\mathrm{Al}-\mathrm{Fe}-\mathrm{Al}$ bağlantı şekillerinin kirletici giderme verimleri 
ve işletme maliyetleri açısından detaylı karşılaştırılması Tablo 2'de ve literatürdeki bazı benzer çalışmaların sonuçları da Tablo 3'de sunulmuştur.

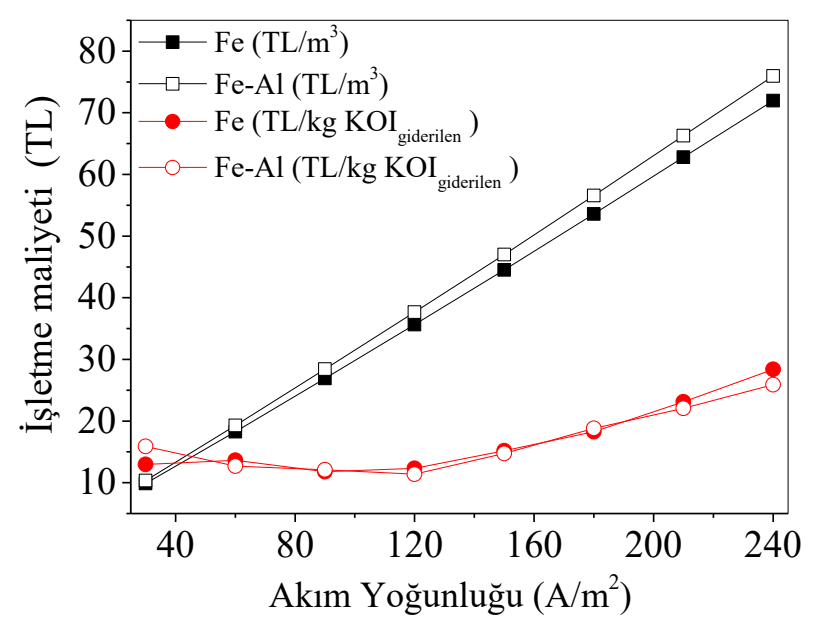

Şekil 7. Akım yoğunluğunun işletme maliyetlerine etkisi (pH: 7., elektroliz süresi: 30 dak.)

Tablo 2. Optimum EC şartlarında hibrit ve hibrit olmayan bağlantı şekillerine ait deney sonuçlarının karşılaştırılması

\begin{tabular}{|c|c|c|}
\hline \multirow[t]{2}{*}{ Parameter } & \multicolumn{2}{|c|}{$\begin{array}{l}\text { Elektrot Materyali ve Dizilim Şekli } \\
\qquad(\text { A-C-A-C) }\end{array}$} \\
\hline & Fe-Fe-Fe-Fe & Fe-Al-Fe-Al \\
\hline Elektroliz (İşletme) Süresi (dak.) (optimum) & 30 & 30 \\
\hline Atıksuyun Başlangıç pH'ı (optimum) & 7 & 7 \\
\hline Akım Yoğunluğu (A/m²) (optimum) & 120 & 120 \\
\hline KOİ giderimi $(\%)$ & 80 & 91 \\
\hline Bulanıklık giderimi (\%) & 92 & 97 \\
\hline Toplam azot giderimi $(\%)$ & 97,7 & 99,9 \\
\hline Toplam fosfor giderimi $(\%)$ & 98,3 & 99,9 \\
\hline Renk giderimi (\%) & 94 & 99 \\
\hline AKM giderimi $(\%)$ & 98 & 99 \\
\hline Elektrot tüketimi $\left(\mathrm{kg} / \mathrm{m}^{3}\right)$ & 9,93 & 9,94 \\
\hline Enerji tüketimi $\left(\mathrm{kWh} / \mathrm{m}^{3}\right)$ & 3,32 & 3,30 \\
\hline Çamur oluşumu $\left(\mathrm{kg} / \mathrm{m}^{3}\right)$ & 12,83 & 13,05 \\
\hline Toplam İşletme Maliyeti (TL/kg KOİ giderilen) & 12,31 & 11,40 \\
\hline Toplam İşletme Maliyeti (TL/m³) & 35,65 & 37,66 \\
\hline
\end{tabular}

Tablo 3. Literatürdeki bazı çeşitli içki (damıtım) fabrikası atıksularının elektrokimyasal yöntemlerle arıtım sonuçları

\begin{tabular}{|c|c|c|c|c|c|c|c|c|}
\hline Atıksu tipi & Proses tipi & $\begin{array}{c}\text { Elektrot } \\
\text { materyali }\end{array}$ & $\begin{array}{c}\text { Akım } \\
\text { yoğunluğu } \\
\left(\mathrm{A} / \mathrm{m}^{2}\right)\end{array}$ & $\begin{array}{c}\text { İşletme } \\
\text { süresi } \\
(\text { dak. })\end{array}$ & $\begin{array}{c}\text { Giriş KOİ } \\
(\mathrm{mg} / \mathrm{L})\end{array}$ & $\begin{array}{c}\text { KOİ } \\
\text { giderimi } \\
(\%)\end{array}$ & $\begin{array}{c}\text { Isletme } \\
\text { maliyeti } \\
\left(\mathrm{TL} / \mathrm{m}^{3}\right)\end{array}$ & $\begin{array}{c}\text { Ref. } \\
\text { Alkol } \\
\text { damıtım }\end{array}$ \\
atıksuyu & $\mathrm{EC}$ & $\mathrm{Al}$ & $30 \mathrm{~V}$ & 150 & 128000 & 86 & - \\
\hline
\end{tabular}




\begin{tabular}{|c|c|c|c|c|c|c|c|c|}
\hline $\begin{array}{c}\text { Biyo- } \\
\text { özümleme } \\
\text { çıkış suyu }\end{array}$ & $\mathrm{EC}$ & $\mathrm{Fe}$ & 45 & 120 & 15600 & 50 & - & [47] \\
\hline $\begin{array}{c}\text { Alkol } \\
\text { damitım } \\
\text { atıksuyu }\end{array}$ & EC & $\mathrm{Fe}$ & 300 & 60 & 44340 (ort.) & 72 & - & [48] \\
\hline $\begin{array}{c}\text { Biyolojik } \\
\text { arıtma çıkış } \\
\text { suyu }\end{array}$ & EC & $\mathrm{Fe}$ & 39 & 12 & $\begin{array}{c}4600 \text { (TOK } \\
\text { olarak) }\end{array}$ & 73 & - & [49] \\
\hline $\begin{array}{c}\text { Alkol } \\
\text { damıtım } \\
\text { atıksuyu }\end{array}$ & EC & $\begin{array}{c}\text { Eloksallı } \\
\text { Grafit }\end{array}$ & 600 & $0-4$ saat & $\begin{array}{c}13500 \text { (ort.) } \\
\quad(10 \text { kat } \\
\text { seyreltilmiş } \\
\text { değer) }\end{array}$ & 85 & - & [50] \\
\hline $\begin{array}{c}\text { Alkol } \\
\text { damıtım } \\
\text { atıksuyu }\end{array}$ & EC & $\mathrm{Fe}$ & 1200 & 120 & 98400 & $\begin{array}{c}79 \text { (renk } \\
\text { giderimi } \\
\text { olarak) }\end{array}$ & - & [51] \\
\hline $\begin{array}{c}\text { Alkol } \\
\text { damıtım } \\
\text { atıksuyu }\end{array}$ & $\mathrm{EC}+\mathrm{AOP} *$ & $\mathrm{Fe}$ & 30 & 240 & 8500 & 94 & 10 & [52] \\
\hline $\begin{array}{c}\text { Alkol } \\
\text { damitım } \\
\text { atıksuyu }\end{array}$ & EC+Adsorbsiyon & $\begin{array}{c}\text { Al-SS } \\
\text { veya Fe- } \\
\text { SS }\end{array}$ & 182 & 60 & $\sim 18900$ & 80,1 & - & [53] \\
\hline $\begin{array}{c}\text { Alkol } \\
\text { damitım } \\
\text { atıksuyu }\end{array}$ & $\begin{array}{c}\text { EC (son aritma } \\
\text { olarak) }\end{array}$ & SS & $\sim 150$ & 130 & 9310 & 61,6 & - & [54] \\
\hline $\begin{array}{c}\text { Alkol } \\
\text { damitım } \\
\text { atıksuyu }\end{array}$ & EC+ozon & $\mathrm{Fe}$ & 300 & 240 & 2500 & 83 & - & [55] \\
\hline $\begin{array}{c}\text { Bira } \\
\text { fabrikas1 } \\
\text { atıksuyu }\end{array}$ & EC & $\begin{array}{l}\text { Fe-Al- } \\
\text { Fe-Al }\end{array}$ & 60 & 30 & 3620 & 91 & 37,66 & $\begin{array}{c}\text { [Bu } \\
\text { çalışma] }\end{array}$ \\
\hline
\end{tabular}

* AOP: İleri oksidasyon prosesi

\section{SONUÇLAR}

EC prosesi, enerji verimliliği, otomasyona uygunluğu ve ekonomik bir metot olması gibi avantajlarıyla endüstriyel atıksu arıtma uygulamalarında sıklıkla tercih edilmektedir. $\mathrm{Bu}$ çalışmada da tarım-gıda endüstrileri arasında önemli kirletici kaynaklardan biri olan bira fabrikası atıksularının arıtılması için geleneksel EC performansını arttırmak amaciyla literatürde son yıllarda araştırılan hibrit elektrot bağlantıları kullanılmıştır. Atıksuyun yer aldığı elektroliz hücresinde dört adet elektrot, monopolar paralel bağlantı ile işletilerek, anot ve katotların demir ve alüminyum materyalinden oluşturulduğu sekiz farklı bağlantı biçiminin EC performansı incelenmiştir. Anot-Katot-Anot-Katot elektrot diziliminde, en yüksek giderme verimini sağlayan $\mathrm{Fe}-\mathrm{Al}-\mathrm{Fe}-\mathrm{Al}$ hibrit bağlantı şekli ile Fe-Fe-Fe-Fe elektrot dizilimi mukayese edilmiş; KOİ ve bulanıklık giderimleri ile işletme maliyetleri üzerinden değerlendirme yapılmıştır. Elektroliz süresinin 30 dakika, pH'nın 7 ve akım yoğunluğunun $120 \mathrm{~A} / \mathrm{m} 2$ olduğu işletme şartlarında Fe-Fe$\mathrm{Fe}-\mathrm{Fe}$ elektrot bağlantı şekli ile KOİ ve bulanıklık giderimi sırasıyla $\% 80$ ve $\% 92$ olurken, hibrit bağlantı ile işletilen 
reaktörde giderme verimleri artmış ve $\% 91$ ile $\% 97$ olarak elde edilmiştir. Her iki farklı bağlantılı işletme şeklinde arıtılan metreküp atıksu başına işletme maliyeti $\sim 35 \mathrm{TL}$ olarak hesaplanmış ve giderilen kg KOİ başına da $\sim 12$ TL olarak elde edilmiştir.

Deney sonuçlarına göre, bulanıklık, askıda katı madde, renk, toplam azot ve toplam fosfor tamamen uzaklaştırılmış, nispeten düşük şiddette kirletici karakterizasyonuna sahip bira fabrikası atıksuyundan Fe-Al-Fe-Al elektrot bağlantılı EC sistemi ile \% 91 oranında KOİ giderimi elde edilmiş ve EC çıkış suyunda KOİ 315 mg/L'ye kadar düşürülebilmiştir. Ancak, yüksek şiddette olan bira endüstrisi atıksuları için (100000 mg/L KOİ gibi) bu çalışmada kullanılan hibrit bağlantı sistemi, yerel deşarj limitlerine yaklaşmakta yetersiz kalabilir. Bu çalışmanın sonuçlarına dayanarak, gelecekteki çalışmalarda hibrit elektrot bağlantılı EC sistemi benzer karakteristikte atıksular için bir ön arıtma yöntemi olarak kullanılabilir ve yüksek KOİ konsantrasyonlarını bertaraf edebilecek bir anaerobik proses ile desteklenebilir veya bir oksidasyon prosesini takiben, çıkış suyunu iyileştirme amacıyla son arıtma olarak da değerlendirilebilir.

\section{KAYNAKÇA}

[1] A.A. Olajire, "The brewing industry and environmental challenges", J. Clean. Production, pp. 1-21, 2012.

[2] G. Simate, J. Cluett, S. Iyuke, E. Musapatika, S. Ndlovu, L. Walubita, A. Alvarez, "The treatment of brewery wastewater for reuse: state of the art", Desalination, vol. 273 no 2-3, 235-247, 2011.

[3] P. Pal, K. Khairnar, W.N. Paunikar, "Causes and remedies for filamentous foaming in activated sludge treatment plant", Global NEST, vol. 16 no. pp. 762-772, 2014.

[4] L. Braeken, B. Van der Bruggen, C. Vandecasteele, "Regeneration of brewery waste water using nanofiltration", Wat. Res., vol. 38, no. 13, pp. 3075-3082, 2004.

[5] K. Kanagachandran, R. Jayaratne, "Utilization potential of brewery waste water sludge as an organic fertilizer", J. Inst. Brew., vol. 112, pp. 92-96, 2006.

[6] A.G., Brito, J. Peixoto, J.M. Oliveira, J.O., Oliveira, C. Costa, R. Nogueira, A. Rodrigues, Brewery and winery wastewater treatment: Some focal points of design and operation. In: Oreopoulou V., Russ W., editors. Utilization of By-Products and Treatment of Waste in the Food Industry. New York, NY, USA: Springer Science + Business Media Llc.; pp. 109-131, 2007.

[7] Y. Feng., X. Wang, B.E. Logan, H. Lee, "Brewery wastewater treatment using air-cathode microbial fuel cells", Appl. Microbiol. Biotechnol., vol. 78, pp. 873-880, 2008.

[8] L.C. Huei, "Biodegradation of Brewery Effluent Using Packed-Bed Upflow Anaerobic Reactor (PBUAR) and Membrane Bioreactor (MBR)" Bachelor Thesis, Universiti Teknologi Malaysia: Faculty of Civil Engineering, Malaysia, 2005.

[9] W.S. Al-Rekabi, Q. He, W.W. Qiang, "Improvements in wastewater treatment technologies", Pak J. Nutr., vol. 6, no. 2, pp. 104-110, 2007.
[10] T. Janhom, P. Pavasant, S. Wattanachira, "Profiling and monitoring of DOM in brewery wastewater and treated wastewater", Environ. Monit. Assess., vol. 176, pp. $403-$ 418, 2011.

[11] H. Dai, X. Yang, T. Dong, Y. Ke, T. Wang, "Engineering application of MBR process to the treatment of beer brewing wastewater", Modern App. Sci., vol. 4, no. 9, pp. 103-109, 2010.

[12] L. Li, Q. Wang, X. Li, S. Yang, "Sludge reduction during brewery wastewater treatment by hydrolyzation-food chain reactor system", Front. Environ. Sci. Eng. China, vol. 2, no. 1, pp. 32-35, 2008.

[13] M.C., Menkiti, O.D. Onukwuli, "Coag-flocculation studies of Moringa oleifera coagulant (MOC) in brewery effluent: Nephelometric approach", J. Am. Sci., vol. 6, no. 12, pp. 788-806, 2010.

[14] W. Parawira, I. Kudita, M.G. Nyandoroh, R. Zvauya, "A study of industrial anaerobic treatment of opaque beer brewery wastewa- ter in a tropical climate using a full-scale UASB reactor seeded with activated sludge", Process. Biochem., vol. 40, no. 2, pp. 593-599, 2005.

[15] A.G. Rao, T.S.K. Reddy, S.S. Prakash, J. Vanajakshi, J. Joseph, P.N. Sarma, "pH regulation of alkaline wastewater with carbon dioxide: a case study of treatment of brewery wastewater in UASB reactor coupled with absorber", Bioresour. Technol., vol. 98, pp. 2131-2136, 2007.

[16] C. Cronin, K.V. Lo, "Anaerobic treatment of brewery wastewater using UASB reactors seeded with activated sludge, Bioresour. Technol., vol.64, pp., 33-38, 1998.

[17] S.S. Madaeni, Y. Mansourpanah, "Screening membranes for COD removal from dilute wastewater", Desalination, vol. 197, no. 1-3, pp. 23-32, 2006.

[18] M. Bayramoglu, M. Eyvaz, M. Kobya., "Treatment of the textile wastewater by electrocoagulation: economic evaluation", Chem. Eng. J., vol. 128, pp. 155-161, 2007.

[19] M.Y.A. Mollah, P. Morkovsky, J.A.G. Gomes, M. Kesmez, J. Parga, D.L. Cocke, "Fundamentals, present and future perspectives of electrocoagulation" J. Hazard. Mater., vol. 114, pp. 199-210, 2004.

[20] M.Y.A. Mollah, R. Schennach, J.R. Parga. D.L. Cocke, "Electrocoagulation EC-science and applications" J. Hazard. Mater., vol. 84, pp. 29-41, 2001.

[21] S. Elabbas, N. Ouazzani, L. Mandi, F. Berrekhis, M. Perdicakis, S. Pontvianne, M-N. Pons, F. Lapicque, J-P Leclerc, "Treatment of highly concentrated tannery wastewater using electrocoagulation: Influence of the quality of aluminium used for the electrode" J. Hazard. Mater., vol. 319, pp. 69-77, 2016.

[22] T. Yang, B. Qiao, G-C Li, Q-Y. Yang, "Improving performance of dynamic membrane assisted by electrocoagulation for treatment of oily wastewater: Effect of electrolytic conditions", Desalination, vol. 363, pp. 134143, 2015.

[23] M. Al-Shannag, Z. Al-Qodah, K. Bani-Melhem, M.R. Qtaishat, M. Alkasrawi, "Heavy metal ions removal from metal plating wastewater using electrocoagulation: Kinetic study and process performance", Chem. Eng. J. vol. 260, pp. 749-756, 2015. 
[24] F. Ulu, S. Barışçı, M. Kobya, H. Särkkä, M. Sillanpää, "Removal of humic substances by electrocoagulation (EC) process and characterization of floc size growth mechanism under optimum conditions", Sep. Purif. Technol., vol. 133, pp. 246-253, 2014.

[25] S. Kara, E. Gurbulak, M. Eyvaz, E. Yüksel, "Treatment of Winery Wastewater by Electrocoagulation Process", Desal. Wat. Treat. vol. 51, no. 28-30, pp. 5421-5429, 2013.

[26] M. Eyvaz, E. Gürbulak, S. Kara, E. Yüksel.Preventing of Cathode Passivation/Deposition in Electrochemical Treatment Methods - A Case Study on Winery Wastewater with Electrocoagulation. In: Modern Electrochemical Methods in Nano, Surface and Corrosion Science, Chapter 8, pp. 201-238, Dr. M. Aliofkhazraei (Ed.), London: Intechopen, 2014.

[27] M. Bayramoglu, M. Kobya, M. Eyvaz, E. Senturk, "Technical and economic analysis of electrocoagulation for the treatment of poultry slaughterhouse wastewater", Sep. Purif. Technol., vol 51, pp. 404-408, 2006.

[28] F. Ozyonar, B. Karagozoglu, "Investigation of technical and economic analysis of electrocoagulation process for the treatment of great and small cattle slaughterhouse wastewater", Desal. Wat. Treat., vol. 52, pp. 74-87, 2014.

[29] K. Thirugnanasambandham, V. Sivakumar, J.P., Maran, "Response surface modelling and optimization of treatment of meat industry wastewater using electrochemical treatment method", J. Taiwan Institute Chem. Eng. vol. 46, pp. 160 1677, 2015.

[30] G.F.S. Valente, R.C.S. Mendonça, J.A.M. Pereira, L.B. Felix, "Artificial neural network prediction of chemical oxygen demand in dairy industry effluent treated by electrocoagulation", Sep. Purif. Technol., vol. 132, pp. $627-$ 633, 2014.

[31] M. Kobya, A. Akyol, E. Demirbas, M.S. Oncel, "Removal of Arsenic from Drinking Water by Batch and Continuous Electrocoagulation Processes Using Hybrid AlFe Plate Electrodes", Environ. Progress Sustain. Energy, vol. 33, no.1, pp. 131-140, 2014.

[32] F. Ozyonar, "Treatment of Train Industry Oily Wastewater by Electrocoagulation with Hybrid Electrode Pairs and Different Electrode Connection Modes", Int. J. Electrochem. Sci., vol. 11, pp. 1456 - 1471, 2016.

[33] S. Barisci, O. Turkay, "Domestic greywater treatment by electrocoagulation using hybrid electrode combinations", J. Wat. Process Eng., vol. 10, pp. 56-66, 2016.

[34] M. Kobya, M. Bayramoglu, M. Eyvaz, “Technoeconomical evaluation of electrocoagulation for the textile wastewater using different electrode connections" J. Hazard. Mater. vol. 148, no. 1-2, pp. 311-318, 2007.

[35] American Public Health Association (APHA), Standard method for examination of water and wastewater, 21st edn. Washington: APHA, AWWA, WPCF, 2005.

[36] V. Khandegar, A.K. Saroha, "Electrochemical Treatment of Distillery Spent Wash Using Aluminum and Iron Electrodes", Chinese J. Chem. Eng., vol. 20, no. 3, pp. 439-443, 2013.

[37] M. Eyvaz, M. Kirlaroglu, T.S. Aktas, E. Yuksel, "The effects of alternating current electrocoagulation on dye removal from aqueous solutions" Chem. Eng. J. vol. 153, no. 1-3, pp. 16-22, 2009.

[38] C.A. Martínez-Huitle, E. Brillas, "Decontamination of wastewaters containing synthetic organic dyes by electrochemical methods: a general review", App. Catalysis B: Environ., vol. 87, pp. 105-145, 2009.

[39] Z. Zaroual, M. Azzi, N. Saib, E. Chainet, "Contribution to the study of electrocoagulation mechanism in basic textile effluent" J. Hazard. Mater., vol. 131, pp. 73-78, 2006.

[40] J.G. Ibanez, M.M. Singh, Z. Szafran, "Laboratory experiments on electrochemical remediation of the environment Part 4 Color removal of simulated wastewater by electrocoagulation-electrocflotation", J. Chem. Education, vol 75, pp. 1040-1041, 1998.

[41] M. Kobya, H. Hiz, E. Senturk, C. Aydiner, E. Demirbas, "Treatment of potato chips manufacturing wastewater by electrocoagulation", Desalination, vol. 190, pp. 201-211, 2006.

[42] M. Kobya, F. Ulu, U. Gebologlu, E. Demirbas, M.S. Oncel, "Treatment of potable water containing low concentration of arsenic with electrocoagulation: Different connection modes and Fe-Al electrodes", Sep. Purif. Technol., vol. 77, pp. 283-293, 2011.

[43]. M. Kobya, U. Gebologlu, F. Ulu, M.S. Oncel, E. Demirbas, "Removal of arsenic from drinking water by the electrocoagulation using $\mathrm{Fe}$ and $\mathrm{Al}$ electrodes", Electrochimica Acta, vol. 56, pp. 5060-5070, 2011.

[44] M.F. Pouet, A. Grasmick, "Urban wastewater treatment by electrocoagulation and flotation", Wat. Sci. Technol., vol. 31, pp. 275-283, 1995.

[45] G. Chen, "Electrochemical technologies in wastewater treatment”, Sep. Purif. Technol., vol. 38, no.1, pp. 11-41, 2004.

[46] M. P. Wagh, P.D. Nemade, "Treatment of Distillery Spent Wash by Using Coagulation and Electrocoagulation [EC]", American J. Environ. Protection, vol. 3, no. 5, pp. 159-162, 2015.

[47] M. Kumar, F. I. A. Ponselvan, J. R. Malviya, V. C. Srivastava, I. D. Mall, "Treatment of bio-digester effluent by electrocoagulation using iron electrodes," J. Hazard. Mater., vol. 165, pp. 345-352, 2009.

[48] B. M. Krishna, U. N. Murthy, B. Manoj Kumar, and K. S. Lokesh, "Electrochemical pretreatment of distillery wastewater using aluminum electrode," J. Appl. Electrochem., vol. 40, no. 3, pp. 663-673, 2010.

[49] M. Damaraju, D. Bhattacharyya, T Panda, K.K. Kurilla, "Application of a Continuous Bipolar Mode Electrocoagulation (CBME) system for polishing distillery wastewater" E3S Web of Conferences 93, 02005 (2019).

[50] P. Manisankar, C. Rani, S. Viswanathan, "Effect of halides in the electrochemical treatment of distillery effluent”, Chemosphere, vol. 57, pp. 961-966, 2004.

[51] S. Basu, S. Mukherjee, A. Kaushik, V.S. Batra, M. Balakrishnan, "Integrated treatment of molasses distillery wastewater using microfiltration (MF)", J. Environ. Manag., vol. 158, pp. 55-60, 2015.

[52] A.R.A. Aziz, P. Asaithambi, W.M.A.B.D. Daud, "Combination of electrocoagulation with advanced oxidation processes for the treatment of distillery industrial 
effluent", Process Safety Environ. Protec., vol. 99, pp. 227 235, 2016.

[53] N. Kannan, G. Karthikeyan, N. Tamilselvan, "Comparison of treatment potential of electrocoagulation of distillery effluent with and without activated Areca catechu nut carbon", J. Hazard. Mater., vol. 137, no. 3, 1803-1809, 2006.
[54] C. Thakur, V.C. Srivastava, I.D. Mall, "Electrochemical treatment of a distillery wastewater: Parametric and residue disposal study", Chem. Eng. J., vol. 148, no. 3, pp. 496-505, 2009.

[55] P. Asaithambi, M. Susree, R. Saravanathamizhan, M. Matheswaran, "Ozone assisted electrocoagulation for the treatment of distillery effluent”, Desal., vol. 297, pp. 1-7, 2012. 